\title{
An Interactive Approach for Solving Fuzzy Cooperative Continuous Static Games
}

\author{
H.A. Khalifa \\ Institute of Statistical Studies \\ and Research, \\ Cairo University, Egypt
}

\author{
Ramadan A. Zein Eldin \\ Institute of Statistical Studies \\ and Research, \\ Cairo University, Egypt
}

\begin{abstract}
In this paper, a cooperative Continuous static game (F-CCSG) with fuzzy parameters in the cost function of the player is presented. Through the use of the $\alpha$-level sets of fuzzy numbers, the F-CCSG is converted to the corresponding $\alpha$ CCSG and an extended Pareto optimality concept called the $\alpha$-Pareto optimality is introduced. An algorithm for solving the $\alpha$-CCSG is suggested. The algorithm is based mainly on the reference attainable point (ARP) method introduced by Wang et al., [20] and reference direction (RD) method introduced by Narula et al., [7]. One of the major improvement is the reduction of the number of iterations and hence the computational effort required to obtain the final solution. The stability of the first kind without differentiability corresponding to the final solution is determined. To clarify this approach, a numerical example is given for illustration.
\end{abstract}

\section{General Terms}

Game theory, Fuzzy, Interactive Approach.

\section{Keywords}

Game theory; Cooperative continuous static game; Fuzzy numbers; $\alpha$-cut; $\alpha$-Pareto optimality; Reference attainable point; Reference direction; Parametric study.

\section{INTRODUCTION}

Game theory is a useful tool for decision making in the conflict of interests between decision makers in order to select the best joint strategy for them through selecting the best joint desirability. Game theory has wide applications in the social life, economy, policy, engineering, sciences, biological sciences etc., (Navidi et al., [8] and Osborne [10]).

Many decision making problems that arise in the real world need to be modeled as vector optimization problems (VOPs, Continuous static games are another formulations of VOPs (Tomas and Walter [15]) by considering the more general case of multiple decision makers, each with their own cost criterion. This generalization introduces the possibility of competition among the system controls, called "players" and the optimization problem under consideration is therefore termed a "game". Each player in the game controls a specified subset of the system parameters (called his control vector) and seeks to minimize his own scalar cost criterion, subject to specified constraints. Several solution concepts are possible as Nash equilibrium concept Pareto-minimal concept, min-max concept, min-max counterpoint concept, and Stackelberg leader-follower concept (Tomas and Waller [15]).

In their earlier work Sakawa and Yano [17] introduced an interactive decision making method for multi-objective nonlinear programming problem with fuzzy parameters both in the objective function and constraints. Osman [11] gave formulation of different parametric problems in continuous static games. Osman and El-Banna [12] introduced multiobjective nonlinear programming problems with fuzzy parameters in the object functions. Osman et al., [13] studied continuous static games with fuzzy parameters both in the cost functions and constraints. They used the concept of Stackelberg leader with min-max followers solution to solve this problem. Osman et al., [14] introduced large scale continuous static games with fuzzy parameters both in the cost functions and constraints. El- Shafei [3] presented a solution method for Nash cooperative continuous static games by using interactive approach. Kacher and Larbain [5] introduced a concept of equilibrium for a non-cooperative game with fuzzy goals involving fuzzy parameters. This equilibrium is based on Zimmermann's approach for solving linear multi-objective problems with fuzzy gals and the concept of N-S equilibrium introduced by Zhukovskii for a non-cooperative game with payoffs involving unknown parameters in the case of complete ignorance of their behavior. Navidi et al., [9] introduced a new game theoreticbased approach for multi response optimization problem. They used the game theory approach via definition of each response as each player and factors as strategies of each player. Sakawa and Nishizaki [18] introduced two-persons Zero-Sum games with fuzzy multiple payoff matrices. They assumed that each player has a fuzzy goal for each of payoffs. Garagic and Cruz [4] utilized fuzzy set theory in order to incorporate the players' heuristic knowledge of decision making into the framework of conventional game theory or ordinal game theory. They defined a new approach to $\mathrm{N}$ person static fuzzy non cooperative games and developed a solution concept such as Nash for these types of games. Cruz and Simaan [1] proposed theory of ordinal games where, instead of payoff function the players are able to rank-order their decision choices against the choice by the other players.

In this paper, a cooperative continuous static game with fuzzy numbers in the cost function of the player is introduced. The problem is converted to the corresponding deterministic problem. The solution of the deterministic problem is based on the attainable reference point introduced by Wang et al. [20] and the reference direction method introduced by Narula et al., [7]. One of the major improvements is the reduction of the number of iterations and hence the computational effort required to the final solution. The stability set of the first kind corresponding to the final solution is determined.

The paper is organized as in the following sections: In section 2 , a fuzzy cooperative continuous static game is introduced as specific definition and properties. In section 3, an interactive approach for solving the problem considered in section 2 . In section 4 , the stability set of the first kind without differentiability is determined. In section 5, a numerical example is given to clarify the approach given in section 3 and also to clarify the stability set determined in section 4 . Finally, some concluding remarks are reported in section 6 


\section{PROBLEM FORMULATION}

Consider the following cooperative continuous static game (FCCSG) with $\mathrm{m}$ players involving fuzzy parameters in the cost function as

(FCCSG) $\min \mathrm{f}_{\mathrm{i}}\left(\mathrm{x}, \mathrm{u}, \tilde{v}_{i}\right), \quad \mathrm{i}=1,2, \ldots, \mathrm{m}$

Subject to $g_{j}(\mathrm{x}, \mathrm{u})=0, \quad \mathrm{j}=1,2, \ldots, \mathrm{n}$,

$x \in X=\left\{x \in R^{s}: h_{l}(x, u) \geq 0, l=1,2, \ldots, r\right\}$,

Wheref $f_{\mathrm{i}}\left(\mathrm{x}, \mathrm{u}, \tilde{v}_{i}\right), \quad \mathrm{i}=1,2, \ldots, \mathrm{m}$ are convex functions on $R^{n} \times R^{s}, \mathrm{~h}_{\mathrm{l}}(\mathrm{x}, \mathrm{u}), \mathrm{l}=1,2, \ldots, \mathrm{r}$, are concave function on $R^{n} \times R^{s}$, and $g_{j}(\mathrm{x}, \mathrm{u}), \mathrm{j}=1,2, \ldots, \mathrm{n}$ are convex functions on $R^{n} x R^{s}$. It is assumed that there exist a function $u=\varphi(x)$. If $g_{j}(\mathrm{x}, \mathrm{u}), \mathrm{j}=1,2, \ldots, \mathrm{n}$ are differentiable then the Jacobian $\left|\frac{\partial g_{j}(x, u)}{\partial u_{k}}\right| \neq 0 ; \mathrm{j}, \mathrm{k}=1,2, \ldots, \mathrm{n}$ is a neighborhood of a solution point $(x, u), \tilde{v}_{i}=\left(\tilde{v}_{i}, \ldots, \tilde{v}_{m}\right)$ represent a vector of fuzzy parameters that assumed to be characterized as the fuzzy numbers (Dubios and Prade [2]). The real fuzzy numbers $\tilde{v}_{i}, i=1,2, \ldots, m$ form a convex continuous fuzzy subset of the real line whose membership function $\mu_{\tilde{v}}\left(v_{i}\right), i=$ $1,2, \ldots, m$ is defined (kassem and Ammar [6]). Here differentiability assumptions are not needed for the functions $f_{i}\left(x, u, \tilde{v}_{i}\right), i=1,2, \ldots, m$ and $h_{l}(x, u), l=1,2, \ldots, r$. Also, it is assumed the set $\mathrm{X}$ is a regular and compact (i. e., bounded and closed).

Definition 1. (Dubios and Prade [2]). The $\alpha$-level set of the fuzzy numbers $\tilde{v}_{i}, i=1,2, \ldots, m$ is defined as the ordinary set $L_{\alpha}(\tilde{v})$ for which the degree of their membership functions exceed the level $\alpha$ :

$\left\llcorner_{\alpha}(\tilde{v})=\left\{v: \mu_{\tilde{v}_{i}}\left(v_{i}\right) \geq \alpha, i=1,2, \ldots, m\right\}\right.$

For a certain degree of $\alpha$, FCCSG can be rewritten as in the following non fuzzy form (Rockafellar [16])

$(\alpha-\mathrm{CCSG}) \min f_{i}\left(x, u, v_{i}\right), i=1,2, \ldots, m$

Subject to $g_{j}(x, u)=0, j=1,2, \ldots, n$,

$x \in X=\left\{x \in R^{s}: h_{l}(x, u) \geq 0, l=1,2, \ldots, r\right\}$,

$v_{i} \in L_{\propto}\left(\tilde{v}_{i}\right), i=1,2, \ldots, m$

Definition $2: \bar{x} \in X, \bar{v}_{i} \in\left\llcorner_{\alpha}\left(\tilde{v}_{i}\right), i=1,2, \ldots, m\right.$ is said to be on $\alpha$-Pareto optimal solution to the problem ( $\alpha$ - CCSG), if and only if there does not exist another $x \in X, v_{i} \in$ $L_{\propto}\left(\tilde{v}_{i}\right), i=1,2, \ldots, m$ such that :

$f_{i}\left(x, u, v_{i}\right) \leq f_{i}\left(\bar{x}, u, \bar{v}_{i}\right), i=1,2, \ldots, m$,

With the strict inequality holding for at last one $i$, where the corresponding values of the parameters $\bar{v}_{i}, i=1,2, \ldots, m$ are called $\alpha$-level optimal parameters.

From the $\alpha-$ Pareto minimal solution concept to the ( $\alpha-\mathrm{CCSG}$ ) problem, one can prove that a point $\bar{x} \in X$ is an $\alpha$-Pareto minimal solution to ( $\alpha-$ CCSG) problem if and only if $\bar{x}$ is an $\alpha$-Pareto optimal solution to the following $\alpha$-multi objective optimization problem $(\alpha-$ MOP)

$(\alpha-\mathrm{MOP}) \min F_{i}\left(x, a_{i}\right), i=1,2, \ldots m$

Subject to $x \in X=\left\{x \in R^{s}: H_{l}(x) \geq 0, l=1,2, \ldots, r\right\}$,

$a_{i} \in L_{\propto}\left(\tilde{a}_{i}\right), i=1,2, \ldots, m$,

where $F_{i}\left(x, a_{i}\right), i=1,2, \ldots, m$, are convex functions on $R^{s} \times R^{m}$, and $H_{l} 1 \times 1, l=1,2, \ldots, r$ are concave functions on $R^{s}$, and
$F_{i}\left(x, a_{i}\right)=f_{i}\left(\varphi(x), x, v_{i}\right), i=1,2, \ldots, m, \quad H_{l}(\mathrm{x})=$ $h_{l}(\varphi(x), x)$.

Definition 3.

Let $\quad \varphi_{j}(B)=\inf \left(F_{i}\left(x, a_{i}\right), i=1,2, \ldots, m: F_{i}\left(x, a_{i}\right) \leq\right.$ $\left.B_{i}, \mu_{a_{i}}\left(\tilde{a}_{i}\right) \geq \propto, i=1,2, \ldots, m\right\}$ and $B \in R^{m}$. Then, $\alpha$-MOP is said to be stable if $\varphi_{i}(0)$ are finite and there exist scalars $L_{i}$ such that:

$\frac{\varphi_{i}(0)-\varphi_{i}(B)}{\|B\|} \leq\left\llcorner_{i}\right.$, for all $A \neq 0, i=1,2, \ldots, m$. Here, $\alpha-$ MOP is as summed to be stable.

\section{AN INTERACTIVE APPROACH}

Please In this section, an interactive approach for solving the $(\alpha-\mathrm{CCSG})$ can be stated as in the following steps:

Step 1: Ask the decision maker (DM) to specify the initial value of $\alpha,(0<\alpha<1)$ to formulate the problem $(\alpha-\mathrm{MOP})$.

Step 2: Find $\hat{F}_{\mathrm{i}}, \mathrm{i}=1,2, \ldots, \mathrm{m}$, by solving the following problem $\left(P_{1}\right) \max y_{i}, i=1,2, \ldots, m$

Subject to $\quad F_{i}\left(x, a_{i}\right) \geq y_{i}, i=1,2, \ldots, m, \quad x \in X ; a_{i} \in$ $L_{\propto}\left(\widetilde{a}_{i}\right), i=1,2, \ldots, m, y_{i} \in R, i=1,2, \ldots, m$

Step 3: Give an initial reference point. DM provides on initial attainable reference point $\mathrm{F}^{\circ}$ such that $\mathrm{F}^{\circ}>\hat{\mathrm{F}}$. let $\mathrm{I}=$ $\{1,2, \ldots, \mathrm{m}\}, \mathrm{I}^{\circ}=\mathrm{I}, \mathrm{P}=0$ (number of iterations).

Step 4: Search for an $\alpha$-Pareto optimal solution.

Let $\bar{\lambda}_{i}=1 /\left(F_{i}^{p}-\hat{F}_{i}\right), i=1,2, \ldots, m$, and solve the following problem

$\left(\mathrm{P}_{2}\right) \operatorname{Lex} \min \left\{\eta_{\mathrm{i}}, \sum_{\mathrm{i}=1}^{\mathrm{m}}\left|\mathrm{F}_{\mathrm{i}}\left(\mathrm{x}, \mathrm{a}_{\mathrm{i}}\right)-\widehat{\mathrm{F}}_{\mathrm{i}}\right|\right\}, \mathrm{i}=1,2, \ldots, \mathrm{m}$

Subject to $\bar{\lambda}_{\mathrm{i}}\left|\mathrm{F}_{\mathrm{i}}\left(\mathrm{x}, \mathrm{a}_{\mathrm{i}}\right)-\widehat{\mathrm{F}}_{\mathrm{i}}\right| \leq \eta_{\mathrm{i}}, \mathrm{i}=1,2, \ldots, \mathrm{m}$,

$x \in X, a_{i} \in L_{\alpha}\left(\tilde{a}_{i}\right), i=1,2, \ldots, m, 0 \leq \eta_{i} \in R$, to obtain an optimal solution $\left(\mathrm{x}^{\mathrm{p}}, \mathrm{a}^{\mathrm{p}}\right)$.

Step 5: Determine the termination conditions, $\operatorname{WhenF}\left(\mathrm{x}^{\mathrm{p}}, \mathrm{a}^{\mathrm{p}}\right)$ is satisfactory to the DM. let $(\bar{x}, \bar{a})=\left(x^{p}, a^{p}\right)$ be the final solution and go to step 7 . When $F\left(x^{p}, a^{p}\right)$ is not satisfactory and $\mathrm{F}\left(\mathrm{x}^{\mathrm{p}}, \mathrm{a}^{\mathrm{p}}\right)=\mathrm{F}^{\mathrm{p}}$ orp $=\mathrm{m}$, there is no Pareto optimal solution to $(\alpha-\mathrm{MOP})$. Otherwise go to step 6 .

Step 6: Modify the reference point:

(i) The DM chooses $d_{p}$ in $I^{p}$ such that $F_{d_{p}}$ is an unsatisfactory objective in $\left\{F_{i}: i \in I^{p}\right\}$ at $F\left(x^{p}, a^{p}\right)$. Let $\mathrm{I}^{\mathrm{p}+1}=\mathrm{I}^{\mathrm{p}} /\left\{\mathrm{d}_{\mathrm{p}}\right\}$. Separate $\mathrm{I}^{\mathrm{p}+1}$ into two parts:

$\mathrm{I}^{\mathrm{p}}=\left\{\mathrm{i} \in \mathrm{I}^{\mathrm{p}+1}: \mathrm{F}_{\mathrm{i}}\left(\mathrm{x}^{\mathrm{p}}, \mathrm{a}_{\mathrm{i}}^{\mathrm{p}}\right)<\mathrm{F}_{\mathrm{i}}^{\mathrm{p}}\right.$ and $\mathrm{DM}$ wishes to release the value of $\mathrm{F}_{\mathrm{i}}$ at $\mathrm{F}\left(\mathrm{x}^{\mathrm{p}}, \mathrm{a}_{\mathrm{i}}^{\mathrm{p}}\right)$, and $\mathrm{I}_{2}^{\mathrm{p}}=\mathrm{I}^{\mathrm{p}+1} / \mathrm{I}_{1}^{\mathrm{p}}$

(ii) For $\mathrm{i} \in \mathrm{I}^{\mathrm{p}}$, the $\mathrm{DM}$ provides $\nabla_{\mathrm{i}}^{\mathrm{p}}$, the amount to be relaxed for $\mathrm{F}_{\mathrm{i}}$ at $\left(\mathrm{x}^{\mathrm{p}}, \mathrm{a}_{\mathrm{i}}^{\mathrm{p}}\right)$, such that $\nabla_{\mathrm{i}}^{\mathrm{p}} \in\left(0, \mathrm{~F}_{\mathrm{i}}^{\mathrm{p}}-\mathrm{F}_{\mathrm{i}}\left(\mathrm{x}^{\mathrm{p}}, \mathrm{a}^{\mathrm{p}}\right)\right)$. Let

$\mathrm{F}_{\mathrm{i}}^{\mathrm{p}+1}=\mathrm{F}_{\mathrm{i}}\left(\mathrm{x}^{\mathrm{p}}, \mathrm{a}_{\mathrm{i}}^{\mathrm{p}}\right)+\nabla_{\mathrm{i}}^{\mathrm{p}}$. Fori $\in \mathrm{I}_{2}^{\mathrm{p}}, \quad \operatorname{let}_{\mathrm{i}}^{\mathrm{p}+1}=\mathrm{F}_{\mathrm{i}}\left(\mathrm{x}^{\mathrm{p}}, \mathrm{a}_{\mathrm{i}}^{\mathrm{p}}\right)$.

For $i \in \mathrm{I}^{\mathrm{p}} / \mathrm{I}^{\mathrm{p}+1}, \operatorname{letF}_{\mathrm{i}}^{\mathrm{p}+1}=\mathrm{F}_{\mathrm{i}}^{\mathrm{p}}$.

(iii) In the case that $\mathrm{F}_{\mathrm{i}}^{\mathrm{p}+1}=\mathrm{F}_{\mathrm{i}}\left(\mathrm{x}^{\mathrm{p}}, \mathrm{a}_{\mathrm{i}}^{\mathrm{p}}\right)$ for all $\mathrm{i} \in \mathrm{I}^{\mathrm{p}} /\left\{\mathrm{d}_{\mathrm{p}}\right\}$, return to (i) to separate $\mathrm{I}^{\mathrm{p}+1}$ again or to (ii) to increase the amount to be relaxed for some $F_{i}, i \in I_{1}^{p}$ at $F_{i}\left(x^{p}, a^{p}\right)$, if the $\mathrm{DM}$ wishes to do so. Otherwise, stop and there is no $\alpha$-Pareto 
optimal solution. In the case that $\mathrm{F}_{\mathrm{i}}^{\mathrm{p}+1} \neq \mathrm{F}_{\mathrm{i}}\left(\mathrm{x}^{\mathrm{p}}, \mathrm{a}_{\mathrm{i}}^{\mathrm{p}}\right)$ for some $\mathrm{i} \in \mathrm{I}^{\mathrm{p}} /\left\{\mathrm{d}_{\mathrm{p}}\right\}$, go to (iv).

(iv) let $\mathrm{d}=\mathrm{d}_{\mathrm{p}}, \mathrm{F}_{\mathrm{i}}^{1}=\mathrm{F}_{\mathrm{i}}^{\mathrm{p}+1}, \mathrm{i}=1,2, \ldots, \mathrm{m}, \mathrm{i} \neq \mathrm{d}_{\mathrm{p}}$, and solve the following problem $\left(\mathrm{P}_{3}\right) \min \mathrm{F}_{\mathrm{d}}\left(\mathrm{x}, \mathrm{a}_{\mathrm{d}}\right)$

Subject to $F_{i}\left(x, a_{i}\right) \leq F_{i}^{1}, i=1,2, \ldots, m ; i \neq d$

$x \in X, a_{i} \in L_{\propto}\left(\tilde{a}_{i}\right), i=1,2, \ldots, m$,

to obtain an $\alpha$-optimal solution $\left(\mathrm{x}^{1^{\mathrm{p}}}, \mathrm{a}^{1^{\mathrm{p}}}\right)$. When

$F_{d_{p}}\left(x^{1^{p}}, a^{1^{p}}\right)=F_{d_{p}}\left(x^{p}, a_{d_{p}}^{p}\right) \operatorname{orF}_{d_{p}}\left(x^{1^{p}}, a_{d_{p}}^{1_{p}^{p}}\right)$ for $F_{d_{p}}$ is not Satisfactory to the DM, return to (ii) to increase the amount to be relaxed for some $F_{i}, i \in I_{1}^{p}$ at $\left(x^{p}, a^{p}\right)$ if the DM wishes to do so. Otherwise, stop and there is no $\alpha$-Pareto optimal solution.

When $F_{d_{p}}\left(x^{1^{p}}, a_{d_{p}}^{1^{p}}\right) \neq F_{d_{p}}\left(x^{p}, a_{d_{p}}^{p}\right) \operatorname{andF}_{d_{p}}\left(x^{1^{p}}, a_{d_{p}}^{1^{p}}\right)$ for $F_{d_{p}}$ is satisfactory to the DM he/she) provides $\nabla_{d_{p}}^{p}$, the largest amount to be improved for $\mathrm{F}_{\mathrm{d}_{\mathrm{p}}}$ at $\mathrm{F}\left(\mathrm{x}^{\mathrm{p}}, \mathrm{a}^{\mathrm{p}}\right)$, such that $\nabla_{d_{p}}^{p} \in\left[0, F_{d_{p}}\left(x^{p}, a_{d_{p}}^{p}\right)-F_{d_{p}}\left(x^{1^{p}}, a_{d_{p}}^{1_{p}^{p}}\right)\right]$. Let

$\mathrm{F}_{\mathrm{d}_{\mathrm{p}}}^{\mathrm{p}+1}=\mathrm{F}_{\mathrm{d}_{\mathrm{p}}}\left(\mathrm{x}^{\mathrm{p}}, \mathrm{a}_{\mathrm{d}_{\mathrm{p}}}^{\mathrm{p}}\right)-\nabla_{\mathrm{d}_{\mathrm{p}}}^{\mathrm{p}}$.

(v) If $\mathrm{F}_{\mathrm{d}_{\mathrm{p}}}^{\mathrm{p}+1}<\mathrm{F}_{\mathrm{d}_{\mathrm{p}}}\left(\mathrm{x}^{1^{\mathrm{p}}}, \mathrm{a}_{\mathrm{d}_{\mathrm{p}}^{\mathrm{p}}}^{\mathrm{p}}\right)$, letp $=\mathrm{p}+1$ and return to (iii).

Otherwise, $\quad \operatorname{let}\left(\mathrm{x}^{\mathrm{p}+1}, \mathrm{a}^{\mathrm{p}+1}=\left(\mathrm{x}^{1^{\mathrm{p}}}, \mathrm{a}^{1^{\mathrm{p}}}\right)\right.$, letp $=\mathrm{p}+1$ and return to (iv) when $\left(\mathrm{x}^{1^{\mathrm{p}}}, \mathrm{a}^{\mathrm{1}^{\mathrm{p}}}\right)$ is an unique optimal solution of $\left(\mathrm{p}_{3}\right)$ or let $\left(\mathrm{x}^{\mathrm{p}^{\mathrm{p}}}, \mathrm{a}^{1^{\mathrm{p}}}\right)$ be an optimal solution of the following problem. $\left(\mathrm{p}_{4}\right) \min \eta_{\mathrm{i}}, \mathrm{i}=1,2, \ldots, \mathrm{m}$

Subject to

$\bar{\lambda}_{\mathrm{i}}\left|\mathrm{F}_{\mathrm{i}}\left(\mathrm{x}, \mathrm{a}_{\mathrm{i}}\right)-\widehat{\mathrm{F}}_{\mathrm{i}}\right| \leq \eta_{\mathrm{i}}, \mathrm{i}=1,2, \ldots, \mathrm{m}, \mathrm{x} \in \mathrm{X}, \mathrm{a}_{\mathrm{i}} \in L_{\alpha}\left(\tilde{\mathrm{a}}_{\mathrm{i}}\right), \mathrm{i}=$ $1,2, \ldots, \mathrm{m}, 0 \leq \eta_{\mathrm{i}} \in \mathrm{R}$.

Letp $=p+1$ and return to (iii). If $F_{d_{p}}^{p+1} \geq F_{d_{p}}\left(x^{1^{p}}, a_{d_{p}}^{1^{p}}\right)$,

letp $=p+1$ and return to step 4 .

Step 7: Determine the stability set of the first kind $S(\bar{x}, \bar{a})$.

\section{THE DETERMINATION OF THE} STABILITY SET OF THE FIRST KIND

The determination of the stability set of the first kind corresponding to $(\overline{\mathrm{x}}, \overline{\mathrm{a}})$ is determined by applying the following conditions:

$\bar{\delta}_{\mathrm{i}}\left(\overline{\mathrm{a}}_{\mathrm{i}}, \mathrm{c}_{2 \mathrm{i}}\right), \mathrm{i}=1,2, \ldots, \mathrm{m}$

$\bar{\beta}_{\mathrm{i}}\left(\bar{c}_{1 \mathrm{i}}, \mathrm{a}_{\mathrm{i}}\right), \mathrm{i}=1,2, \ldots, \mathrm{m}$

$\bar{\delta}_{\mathrm{i}}, \bar{\beta}_{\mathrm{i}} \geq 0, \mathrm{c}_{1 \mathrm{i}}, \mathrm{c}_{2 \mathrm{i}} \in \mathrm{R},\left[\mathrm{c}_{1 \mathrm{i}}, \mathrm{c}_{2 \mathrm{i}}\right] \in L_{\propto}\left(\tilde{\mathrm{a}}_{\mathrm{i}}\right), \mathrm{i}=1,2, \ldots, \mathrm{m}$

Consider the following three cases:

Case 1: $\bar{\delta}_{\mathrm{i}}>0, \mathrm{i} \in \mathrm{J}_{1} \subset\{1,2, \ldots, \mathrm{m}\}, \bar{\delta}_{\mathrm{i}}=0, \mathrm{i} \notin \mathrm{J}_{1}$.

$\bar{\beta}_{\mathrm{i}}>0, \mathrm{i} \in \mathrm{J}_{2} \subset\{1,2, \ldots, \mathrm{m}\}, \bar{\beta}_{\mathrm{i}}=0, \mathrm{i} \notin \mathrm{J}_{2}$.

Let $M$ be the set of all proper subsets of $\{1,2, \ldots, m\}$. Then $\mathrm{S}_{\mathrm{J}_{1} \mathrm{~J}_{2}}(\overline{\mathrm{x}}, \overline{\mathrm{a}})$ is given by:

$\mathrm{S}_{\mathrm{J}_{1}, \mathrm{~J}_{2}}(\overline{\mathrm{x}}, \overline{\mathrm{a}})=\left\{\left(\mathrm{c}_{1}, \mathrm{c}_{2}\right) \in \mathrm{R}^{2 \mathrm{~m}}: \mathrm{c}_{2 \mathrm{i}}=\overline{\mathrm{a}}_{\mathrm{i}}, \mathrm{i} \in \mathrm{J}_{1}, \mathrm{c}_{2 \mathrm{i}} \leq \overline{\mathrm{a}}_{\mathrm{i}}, \mathrm{i} \notin\right.$

$\left.\mathrm{J}_{1} ; \mathrm{c}_{1 \mathrm{i}}=\overline{\mathrm{a}}_{\mathrm{i}}, \quad \mathrm{i} \in \mathrm{J}_{2}, \mathrm{c}_{1 \mathrm{i}}=\overline{\mathrm{a}}_{\mathrm{i}}, \mathrm{i} \notin \mathrm{J}_{1}\right\}$.

Hence $S_{1}(\bar{x}, \bar{a})=U_{J_{1}, J_{2}}, S_{J_{1}, J_{2}}(\bar{x}, \bar{a})$
Case $2: \bar{\delta}_{i}, \bar{\beta}_{i}=0, i=1,2, \ldots, \mathrm{m}$. Then

$\mathrm{S}_{2}(\overline{\mathrm{x}}, \overline{\mathrm{a}})=\left\{\left(\mathrm{c}_{1}, \mathrm{c}_{2}\right) \in \mathrm{R}^{2 \mathrm{~m}}: \mathrm{c}_{2 \mathrm{i}} \geq \overline{\mathrm{a}}_{\mathrm{i}}, \mathrm{i}=1,2, \ldots, \mathrm{m} ; \mathrm{c}_{1 \mathrm{i}} \leq\right.$ $\left.\overline{\mathrm{a}}_{\mathrm{i}}, \mathrm{i}=1,2, \ldots, \mathrm{m}\right\}$ and

Case 3: $\bar{\delta}_{\mathrm{i}}, \bar{\beta}_{\mathrm{i}}>0, \mathrm{i}=1,2, \ldots, \mathrm{m}$. Then

$\mathrm{S}_{3}(\overline{\mathrm{x}}, \overline{\mathrm{a}})=\left\{\left(\mathrm{c}_{1}, \mathrm{c}_{2}\right) \in \mathrm{R}^{2 \mathrm{~m}}: \mathrm{c}_{2 \mathrm{i}}=\overline{\mathrm{a}}_{\mathrm{i}}, \mathrm{i}=1,2, \ldots, \mathrm{m} ; \mathrm{c}_{1 \mathrm{i}} \leq\right.$ $\left.\overline{\mathrm{a}}_{\mathrm{i}}, \mathrm{i}=1,2, \ldots, \mathrm{m}\right\}$ Thus $\mathrm{S}(\overline{\mathrm{x}}, \overline{\mathrm{a}})=\mathrm{U}_{\mathrm{q}=1}^{3} \mathrm{~S}_{\mathrm{q}}(\overline{\mathrm{x}}, \overline{\mathrm{a}})$.

\section{NUMERICAL EXAMPLE}

Consider a tow player game with the following cost functions

$\mathrm{F}_{1}\left(\mathrm{x}, \tilde{\mathrm{a}}_{1}\right)=\left(\mathrm{x}_{1}-\tilde{\mathrm{a}}_{1}\right)^{2}+\left(\mathrm{x}_{2}-1\right)^{2}$

$\mathrm{F}_{2}\left(\mathrm{x}, \tilde{\mathrm{a}}_{2}\right)=\left(\mathrm{x}_{1}-1\right)^{2}+\tilde{\mathrm{a}}_{2}\left(\mathrm{x}_{2}-2\right)^{2}$,

When player 1 controls $\mathrm{x}_{1}$ and player 2 controls $\mathrm{x}_{2} ; \mathrm{x}_{1}, \mathrm{x}_{2} \in \mathrm{R}$, with $\mathrm{x}_{1}-4 \leq 0, \mathrm{x}_{2}-4 \leq 0 ; \mathrm{x}_{1}, \mathrm{x}_{2} \geq 0$ and with membership function

国 $_{a_{\mathrm{i}}}\left(a_{\mathrm{i}}\right)=\left[\begin{array}{cl}0 & -\infty<\mathrm{a}_{\mathrm{i}}<\mathrm{e}_{\mathrm{i} 1} \\ \frac{\mathrm{a}_{\mathrm{i}}-\mathrm{e}_{\mathrm{i} 1}}{\mathrm{e}_{\mathrm{i} 2}-\mathrm{e}_{\mathrm{i} 1}} & \mathrm{e}_{\mathrm{i} 1}<\mathrm{a}_{\mathrm{i}}<\mathrm{e}_{\mathrm{i} 2} \\ 1 & \mathrm{e}_{\mathrm{i} 2}<\mathrm{a}_{\mathrm{i}}<\mathrm{e}_{\mathrm{i} 3} \mathrm{i}=1,2 \\ \frac{\mathrm{a}_{1}-\mathrm{e}_{\mathrm{i} 4}}{\mathrm{e}_{\mathrm{i} 3}-\mathrm{e}_{\mathrm{i} 4}} & \mathrm{e}_{\mathrm{i} 3}<\mathrm{a}_{\mathrm{i}}<\mathrm{e}_{\mathrm{i} 4} \\ 0 & \mathrm{e}_{\mathrm{i} 4}<\mathrm{a}_{\mathrm{i}}<\infty\end{array}\right.$

let $\tilde{\mathrm{a}}_{1}=(2,3,5,6)$ and $\tilde{\mathrm{a}}_{2}=(4,5,9,10)$. Taking $\alpha=0.5$ then

$\mathrm{a}_{1} \in[2.5,5.5]$ and $\mathrm{a}_{2} \in[4.5,9.5]$

The equivalent ( $\alpha-$ CCSG) becomes

$\min \mathrm{F}_{1}\left(\mathrm{x}, \mathrm{a}_{1}\right)=\left(\mathrm{x}_{1}-\mathrm{a}_{1}\right)^{2}+\left(\mathrm{x}_{2}-1\right)^{2}$

$\min F_{2}\left(x_{1}, a_{2}\right)=\left(x_{1}-1\right)^{2}+a_{2}\left(x_{2}-2\right)^{2}$

Subject to $\mathrm{x}_{1}-4 \leq 0, \mathrm{x}_{2}-4 \leq 0, \mathrm{x}_{1} \geq 0, \mathrm{x}_{2} \geq 0$,

$\mathrm{a}_{1} \in[2.5,5.5], \mathrm{a}_{2} \in[4.5,9.5]$.

Step 2: Solve problem $\left(\mathrm{f}_{1}\right)$ to get $\widehat{F}$

$\max y_{\mathrm{i}}, \mathrm{i}=1,2$

Subject to $\left(\mathrm{x}_{1}-\mathrm{a}_{1}\right)^{2}+\left(\mathrm{x}_{2}-1\right)^{2} \geq \mathrm{y}_{1}$,

$\left(\mathrm{x}_{1}-1\right)^{2}+\mathrm{a}_{2}\left(\mathrm{x}_{2}-2\right)^{2} \geq \mathrm{y}_{2}, \mathrm{x}_{1}-4 \leq 0, \mathrm{x}_{2}-4 \leq 0$

$\mathrm{x}_{1} \geq 0, \mathrm{x}_{2} \geq 0$,

$2.5 \leq \mathrm{a}_{1} \leq 5.5,4.5 \leq 4.5 \leq \mathrm{a}_{2} \leq 9.5$,

$0 \leq \mathrm{y}_{1} \in \mathrm{R}, \mathrm{i}=1,2$.

The solution is

$$
\begin{gathered}
\left(\hat{\mathrm{x}}_{1}, \hat{\mathrm{x}}_{2}, \hat{\mathrm{a}}_{1}, \hat{\mathrm{a}}_{2}\right)=(0.4,2.75,3.8,4.6), \hat{\mathrm{F}}\left(\hat{\mathrm{x}}_{1}, \hat{\mathrm{x}}_{2}, \hat{\mathrm{a}}_{1}, \hat{\mathrm{a}}_{2}\right) \\
=(2.9478,14.967)^{\mathrm{T}}
\end{gathered}
$$

Step 3: Ask the DM to provide an initial reference point $\mathrm{F}^{\circ}$ such that $\mathrm{F}^{\circ}>\hat{\mathrm{F}}$.

$\mathrm{F}_{1}^{\circ} \in[14,17] ? 17, \quad \mathrm{~F}_{2}^{\circ} \in[3,5] ? 5$

$\mathrm{F}^{\circ}=(5,17)^{\mathrm{T}}$.

Find $\lambda_{1}=0.333 \quad \lambda_{2}=0.47619$

Solve the following problem

Lexmin $\left\{\eta_{\mathrm{i}},\left|\left(\mathrm{x}_{1}-\mathrm{a}_{1}\right)^{2}+\left(\mathrm{x}_{2}-1\right)^{2}-5\right|\right.$

$$
+\left|\left(x_{1}-1\right)^{2}+a_{2}\left(x_{2}-2\right)^{2}-17\right| \text {, }
$$$$
\mathrm{i}=1,2
$$ 
Subject to $\frac{1}{3}\left|\left(x_{1}-a_{1}\right)^{2}+\left(x_{2}-1\right)^{2}\right| \leq \eta_{1}$

$$
\frac{1}{2.1}\left|\left(x_{1}-1\right)^{2}+a_{2}\left(x_{2}-2\right)^{2}\right| \leq \eta_{2}
$$

$\mathrm{x}_{1}-4 \leq 0, \mathrm{x}_{2}-4 \leq 0, \mathrm{x}_{1} \geq 0, \mathrm{x}_{2} \geq 0$,

$2.5 \leq \mathrm{a}_{1} \leq 5.5, \quad 4.5 \leq \mathrm{a}_{2} \leq 9.5$

The solution is $\left(\mathrm{x}_{1}^{\circ}, \mathrm{x}_{2}^{\circ}, \mathrm{a}_{1}^{\circ}, \mathrm{a}_{2}^{\circ}\right)=(0.4,2.75,3.8,4.6)^{\mathrm{T}}$,

$$
\mathrm{F}\left(\mathrm{x}^{\circ}, \mathrm{a}^{\circ}\right)=(14.4475,14.6225)^{\mathrm{T}} \text {. }
$$

The iteration result is:

$\left(\mathrm{x}^{\circ}, \mathrm{a}^{\circ}\right)=(0.4,2.75,3.4,4.6)$,

$\left.\mathrm{F}\left(\mathrm{x}^{\circ}, \mathrm{a}^{\circ}\right)=(14.4475,14.6225) \mathrm{T}\right)$,

Reference point and $\hat{F}$ are $\mathrm{F}^{\circ}=(5,17)^{\mathrm{T}}, \hat{\mathrm{F}}=(2.95,14.97)$ is the solution satisfactory: $\mathrm{Y} / \mathrm{N}$ ? Yes. To determine $S(0.4,2.75,3.8,4.6)$, let us apply the following conditions:

$\bar{\delta}_{1}\left(3.8-\mathrm{c}_{21}=0, \bar{\delta}_{2}\left(4.6-\mathrm{c}_{22}\right)=0\right.$
$\bar{\beta}_{1}\left(\mathrm{c}_{11}-3.8\right)=0, \bar{\beta}_{2}\left(\mathrm{c}_{12}-4.6\right)=0$,
$\bar{\delta}_{1}, \bar{\delta}_{2}, \bar{\beta}_{1}, \bar{\beta}_{2} \geq 0,\left[\mathrm{c}_{11}, \mathrm{c}_{21}\right] \in\left\llcorner_{\propto}\left(\tilde{\mathrm{a}}_{\mathrm{i}}\right)\right.$.

We have $\mathrm{J}_{1 \mathrm{k}}$ and $\mathrm{J}_{2 \mathrm{k}} \in\{1,2\}$. For $\mathrm{J}_{11}=\{1\}, \bar{\delta}_{1}>0, \bar{\delta}_{2}=0$,

For $J_{2 \mathrm{k}}=\{2\}, \bar{\beta}_{1}=0, \bar{\beta}_{2}>0$, then

$\mathrm{S}_{\mathrm{I}_{11}, \mathrm{~J}_{21}}=(0.4,2.75,3.8,4.6)=\left\{\left(\mathrm{c}_{1}, \mathrm{c}_{2}\right) \in \mathrm{R}^{4}: \mathrm{c}_{21}=3.8, \mathrm{c}_{22} \geq\right.$

$\left.4.6, c_{11} \leq 3.8, c_{12}=4.6\right\}$.

For , $\mathrm{J}_{12}=\{2\}, \bar{\delta}_{1}=0, \bar{\delta}_{2}>0$, for $\mathrm{J}_{22}=\{1\}, \bar{\beta}_{1}>0, \bar{\beta}_{2}=0$

Then

$\mathrm{S}_{\mathrm{J}_{12} \mathrm{~J}_{22}}(0.4,2.75,3.8,4.6)=\left\{\left(\mathrm{c}_{1}, \mathrm{c}_{2}\right) \in \mathrm{R}^{4}: \mathrm{c}_{21} \geq 3.8, \mathrm{c}_{22}=\right.$ $\left.4.6, \mathrm{c}_{11}=3.8, \mathrm{c}_{12} \leq 4.6\right\}$,

For $J_{13}=\{1,2\}, \bar{\delta}_{1}>0, \bar{\delta}_{2}>0$, for $_{23}=\phi, \bar{\beta}_{1}, \bar{\beta}_{2}=0$,

Then

$$
\begin{aligned}
\mathrm{S}_{\mathrm{J}_{13}, \mathrm{~J}_{23}}(0.4,2.75,3.8 & , 4.6) \\
& =\left\{\left(\mathrm{c}_{1}, \mathrm{c}_{2}\right) \in \mathrm{R}^{4}: \mathrm{c}_{21}=3.8, \mathrm{c}_{22}=4.6, \mathrm{c}_{11}\right. \\
& \left.\leq 3.8, \mathrm{c}_{12} \leq 4.6\right\} .
\end{aligned}
$$

for $J_{14}=\phi, \bar{\delta}_{1}, \bar{\delta}_{2}=0$, for $_{24}=\{1,2\}, \bar{\beta}_{1}, \bar{\beta}_{2}>0$

Then

$$
\begin{aligned}
& \mathrm{S}_{\mathrm{J}_{14}, \mathrm{~J}_{24}}(0.4,2.75,3.8,4.6) \\
&=\left\{\left(\mathrm{c}_{1}, \mathrm{c}_{2}\right) \in \mathrm{R}^{4}: \mathrm{c}_{21} \geq 3.8, \mathrm{c}_{22} \geq 4.6, \mathrm{c}_{11}\right. \\
&\left.=3.8, \mathrm{c}_{12}=4.6\right\} .
\end{aligned}
$$

Thus

$$
\mathrm{S}(0.4,2.75,3.8,4.6)=\mathrm{U}_{\mathrm{t}=1}^{4} \mathrm{~S}_{\mathrm{J}_{1 \mathrm{t}} \mathrm{J}_{2 \mathrm{t}}}(0.4,2.75,3.8,4.6)
$$

\section{CONCLUDING REMARKS}

In this paper, a cooperative continuous static game (F CCSG) with fuzzy parameters in the cost functions of the player have been studied. An interactive approach based on the attainable reference point introduced by Wang et al.,[20] and the reference direction method introduced by Narula et al.,([7] has been applied to solve the deterministic problem $(\alpha$ - CCSG) corresponding to the F-CCSG. The stability of the first kind has been determined corresponding to the final solution. However, WINQSB package has been used to obtain the results.

\section{REFERENCES}

[1] Cruz, J.B., and Simaan, M., (2000). Ordinal games and generalized Nash and Stackelberg solutions, Journal of optimization theory and applications, (107): $205-222$.

[2] Dudois, D., and Prade, H., (1980). Fuzzy Sets and Systems: theory and Applications, Academic Press, New York.

[3] El-Shafei, K.M.M., (2007). An interactive approach for solving Nash cooperative continuous static games (NCCSG), International Journal of contemporary Mathematical sciences, (2):1147 - 1162.

[4] Garagic, D., and Cruz, B.J., (2003). An approach to fuzzy Noncooperative Nash games. Journal of Optimization theory and applications, (118): 475 - 491

[5] Kacher, F., and Larbani, M., (2008). Existence of equilibrium solution for a non-cooperative game with fuzzy goals and parameters, Fuzzy Sets and Systems, (159): $164-176$.

[6] Kassem, M.A., and Ammar.E. E., (1996). A parametric study of multiobjective nonlinear programming problems with fuzzy parameters in the objective functions, Fuzzy Sets and Systems, (8): 187-196.

[7] Narula, S. C., Kirilov, L., and Vassilev, V., (1993). An Interactive Algorithm for Solving Multiple Objective Nonlinear Programming Problems, Multiple Criteria Decision Making, Proceeding of the 10th International Conference: Expand and Enrich the Domain of Thinking and Application, Springer-Verlag, Berlin.

[8] Navidi, H., Ketabchi, S., and Messi, M., (2011). An introduction to Game Theory. (In Farsi) Shahed University.

[9] Navidi, R.H., Amiri, A., and Kamranrad, R., (2014). Multi responses optimization through game theory approach, International Journal of Industrial Engineering and production Research, (25): 215 - 224.

[10] Osborne, M. J., (2003). A Course in Game Theory. Oxford University Press.

[11] Osman, M., (1984). Different parametric problems in Continuous Static Games, The 1st ORMA conference, M.T.C., Cairo Egypt.

[12] Osman, M., and El-Banna, A., (1993). Stability of multiobjective nonlinear programming problems with fuzzy parameters, Mathematics and Computers in Simulation, (35): 321-326.

[13] Osman, M., El-Banna, A., and Kamel, M., (1999). On Fuzzy Continuous Static Games: Stackberg leader with min-max followers, Fuzzy Mathematics, (2): 259-266.

[14] Osman, M., El-Banna, A., and Amer, A., (1999). Study large scale fuzzy Nash equilibrium solutions, Fuzzy Mathematics, (2): 267-275.

[15] Tomas, L., and Waiter, J., (1981). Optimality in Parametric Systems, John Wiley, Inc., New York.

[16] Rockafellar, R., (1967). Duality and stability in extremum problems involving convex functions. Pacific Journal of Mathematics, (21): 167-181. 
[17] Sakawa, M., and Yano, H., (1989). Interactive decision making for multiobjective nonlinear programming problems with fuzzy parameters, Fuzzy Sets and Systems, (29):315-326.

[18] Sakawa, M., and Nishizaki, I., (1994). Max-min solution for fuzzy multi objective matrix games, Fuzzy sets and Systems, (67):53-69.
[19] Tomas,L., and Walter,J., (1981). Optimality in Parametric Systems, John Wiley, Inc., New York.

[20] Wang, X.M., Qin, Z.L., and Hu, Y.D., (2001). An interactive algorithm for solving multi criteria decision making: the attainable reference point method, IEEE Transactions on systems, Man, and cybernetics - part A: systems and Humans, (31): 194 - 198. 